\title{
PREDICTION OF THE CARCASS VALUE OF YOUNG HOLSTEIN-FRIESIAN BULLS BASED ON LIVE BODY MEASUREMENTS*
}

\author{
Paulina Pogorzelska-Przybyłek ${ }^{1 *}$, Zenon Nogalski ${ }^{1}$, Zofia Wielgosz-Groth ${ }^{1}$, Rafał Winarski ${ }^{2}$, \\ Monika Sobczuk-Szul ${ }^{1}$, Patrycja Łapińska ${ }^{1}$, Cezary Purwin ${ }^{3}$ \\ ${ }^{1}$ Department of Cattle Breeding and Milk Quality Evaluation, \\ ${ }^{2}$ Department of Commodity Science of Animal Raw Materials, \\ ${ }^{3}$ Department of Animal Nutrition and Feed Management, \\ University of Warmia and Mazury in Olsztyn, Oczapowskiego 5, 10-719 Olsztyn, Poland \\ •Corresponding author: paulina.pogorzelska@uwm.edu.pl
}

\begin{abstract}
The aim of this study was to determine the suitability of ultrasound and zoometric measurements and visual muscle scoring for predicting the carcass value of 167 young Holstein-Friesian (HF) bulls. Zoometric and ultrasound measurements were performed and live muscle scoring was estimated before slaughter. After slaughter, hot carcass weight (HCW) was determined and carcasses were assigned to conformation and fat classes according to the EUROP system. Multiple regression equations were derived to estimate the weight, conformation and fatness of carcasses. $\mathrm{HCW}$ was estimated using the following equations: $\hat{Y}=1.507 x_{1}+1.103 x_{2}+4.043 x_{3}+5.53 x_{4}+0.379 x_{5}+$ $+8.076 x_{6}-678.93\left(R^{2}=0.892 ; S_{y}=16.28\right)$ and $\hat{Y}=2.525 x_{4}+0.579 x_{7}+0.451 x_{8}-134.17\left(R^{2}=0.943 ;\right.$ $\left.S_{y}=11.84\right)$; independent variables $x_{1}-$ height at sacrum $(\mathrm{cm}) ; x_{2}-$ chest girth $(\mathrm{cm}) ; x_{3}-$ pelvic width (cm); $x_{4}$ - pelvic length (cm); $x_{5}$ - thickness of $M$. gluteo-biceps $(\mathrm{mm}) ; \mathrm{x}_{6}$ - intravital muscle scoring (points); $x_{7}$ - thickness of $M$. longissimus dorsi $(\mathrm{mm}) ; \mathrm{x}_{8}$ - live weight $(\mathrm{kg})$. Validation of the first regression equation revealed overestimation of $\mathrm{HCW}$ by $1.25 \%$ on average, while validation of the second equation revealed its underestimation by $1.85 \%$ on average. It was found that intravital muscle scoring and selected ultrasound and zoometric measurements of HF bulls can be used in formulating regression equations for predicting the carcass value of live animals. The proposed models enable predicting the carcass value of young bulls with satisfactory accuracy, thus contributing to an objective live beef cattle assessment.
\end{abstract}

Key words: prediction, carcass value, body measurements

\footnotetext{
*This study was carried out as part of the project entitled Optimization of beef production in Poland in accordance with the "fork-to-farm" strategy, No. PO IG 01.03.01-00-204, co-financed by the European Union from the European Regional Development Fund within the Innovative Economy Operational Programme 2007-2013.
} 
Carcass value can be estimated based on body measurements and assessment of lean and fat percentages in the live animal. Due to their high repeatability, the results of such evaluations can be used to identify genetically valuable animals with respect to carcass tissue composition and quality (Conroy et al., 2009), thus enabling their early selection. Live body measurements can also be used to choose the proper cattle fattening system and to predict the slaughter value of animals (Guidelines for Uniform Beef Improvement Programs, 2010; Conroy et al., 2009; Bergen et al., 2005; Tait et al., 2005). According to Słoniewski et al. (2001), ultrasound measurement of muscle thickness in the lumbar region is correlated with carcass dressing percentage $(\mathrm{R}=0.61, \mathrm{P} \leq 0.01)$. Visual muscle scoring can also be used to predict the carcass value of cattle (Gil et al., 2007), in particular in small abattoirs where slaughter value is not assessed or a subjective organoleptic evaluation is performed by skilled graders. Conroy et al. (2010) demonstrated that pre-slaughter muscular scores were significantly correlated with kill-out proportion and carcass value $(\mathrm{R}=0.82$ and $\mathrm{R}=0.72$, respectively). In large meat-processing plants, bovine carcasses are categorized into conformation and fat classes according to the EUROP grid method. The EUROP classification scheme was introduced in Poland to standardize carcass grading and to ensure a common classification standard and a uniform price reporting system throughout the European Union. In Poland, livestock dealers are usually involved in cattle buying and selling operations. Cattle producers get paid on a live basis - dealers purchasing live animals determine their weight and estimate carcass quality grade. Meat processing plants purchase cattle on a carcass basis - carcasses are priced based on HCW or in accordance with the EUROP system. Due to pencil shrink (a percentage deduction from the liveweight of the cattle due to their overfeeding or excessive watering) and high carcass yield, dealers often receive a bonus that in direct sales would go to producers of finishing cattle. In order to make pre-slaughter estimates of beef carcasses more objective and to minimize the risk of unfair settlements, leanness and fatness could be estimated in live animals with the use of ultrasonic devices. Positive correlations have been found between ultrasound and zoometric measurements or estimated carcass lean content and carcass dressing percentage or the percentage content of valuable cuts and meat in the carcass (Brethour, 2000; Greiner et al., 2003 b; Tait et al., 2005; Drennan et al., 2008; Conroy et al., 2009; Indurain et al., 2009; Conroy et al., 2010). Młynek and Litwińczuk (1999) proposed a set of traits that could be measured in live animals to determine livestock classes and, indirectly, the carcass value of beef cattle fattened to heavy weights. Ultrasound technology, which is a convenient, rapid and inexpensive measuring tool, can be effectively used for predicting the body composition of live animals. In a study by Bergen et al. (2005), correlation values between predicted and actual carcass composition ranged from $\mathrm{R}^{2}=0.53$ to 0.74 . In Poland, Trela and Choroszy (2011) found highly significant correlations between the thickness of the $M$. longissimus dorsi at the 12th rib site and meat weight in the carcass $(\mathrm{R}=0.73)$. The most common carcass traits evaluated with ultrasonic devices include subcutaneous fat thickness and the cross-sectional area of M. longissimus dorsi (measured at the 12th-13th rib site); in some cases, muscle and fat thickness are also measured over the rump to improve estimation 
accuracy (Realini et al., 2001; Greiner et al., 2003 a; Bergen et al., 2005; Tait et al., 2005).

Cattle population data collected in 2012 revealed a growing interest among farmers in beef production, which in Poland is based mainly on Holstein-Friesian (HF) dairy herds. Cull dairy cows, young bulls and - to a lesser extent - heifers are intended for beef slaughter. In 2011, bulls (627 324 head) accounted for 53\% (on a live weight basis) of cattle slaughtered for beef in Poland (Central Statistical Office, 2013).

The objective of this study was to determine the suitability of ultrasound, zoometric measurements and live muscle scoring for predicting the carcass value of young HF bulls.

\section{Material and methods}

\section{Animals}

The experimental materials comprised 167 young HF bulls purchased by a meat processing plant from individual farmers in the region of Warmia and Mazury, between 4 January 2011 and 29 April 2011. Young bulls of known origin, aged 15-27 months, were raised in a semi-intensive production system, and they were fed grass silage and maize silage supplemented with concentrate. The bulls were transported to the lairage 20-24 hours prior to slaughter, and they were kept in individual boxes equipped with drinkers.

\section{Live body measurements}

Bulls were weighed and live muscle scoring was determined in the lairage, immediately before slaughter. Zoometric and ultrasound measurements were performed. A visual appraisal of muscle score was performed on a scale of 1 (low lean content) to 10 (very high lean content). It "describes the shape of cattle independent of the influence of fatness. Muscling is the degree of thickness or convexity of an animal relative to its frame size" (McKiernan, 2007). A similar but not identical method for evaluating the conformation of animals to that presented in the paper, was applied by Choroszy et al. (2010). The following live body measurements were performed: height at withers, height at sacrum, forechest width, chest depth (from the withers to the lowest point of the sternum, behind the elbows), chest girth, pelvic width (between the processes of the hip bone), pelvic length (from the external border of the coxal tuber to the external border of the ischial tuberosity), trunk length (from the withers to the point of intersection with the line connecting the coxal tubers with the spine). The following ultrasound measurements were performed: 1) thickness of M. gluteo-biceps and thickness of subcutaneous rump fat (over M. gluteo-biceps, at the point of intersection of the line connecting the coxal tuber with the ischial tuberosity and the vertical line passing through the greater trochanter); 2) thickness of $M$. longissimus dorsi and thickness of subcutaneous back fat (at the level of the 12th-13th thoracic vertebrae, over M. longissimus dorsi), cross-sectional area of 
M. longissimus dorsi. Ultrasound measurements were performed by one person with the use of the Mysono 201 device (Medison Co.), equipped with a $170 \mathrm{~mm}$ linear probe (PB-MYL2-5/170 CD), operating in the 2-5 MHz frequency range. The registered scans were read out and interpreted in the laboratory after the measurements had been completed. The skin was shaved, and measurements were carried out using ultrasound gel to ensure optimal contact between the transducer head and the skin.

\section{Carcass measurements}

The experimental bulls were slaughtered in accordance with industrial standards. After post-slaughter analysis and determination of HCW (hot carcass weight), a trained grader categorized carcasses into conformation and fat classes according to the EUROP system. The results of carcass classification were converted to a 15-point grading scale $(1-15)$.

\section{Statistical analysis}

The coefficients of simple correlation between the independent variables were calculated to eliminate highly correlative traits. The dataset for $167 \mathrm{HF}$ bulls was randomly split into a training set (data for 130 animals) and a validation set (data for 37 animals) by the simple random sampling method. Multiple regression equations for predicting HCW and carcass quality were derived using stepwise regression based on backward elimination. Variables with the highest $\mathrm{P}$ value were successively eliminated from the equations, leaving only independent variables with $\mathrm{P} \leq 0.05$. The validation set was used to determine the accuracy of estimation. All calculations were done using Statistica ver. 10.0 software.

\section{Results}

All analysed bulls varied widely with respect to age and live weight (Table 1). Their average age was 22 months, average live weight ranged from 450 to $750 \mathrm{~kg}$ and average HCW was $327.5 \mathrm{~kg}$. Average height at sacrum was $138.8 \mathrm{~cm}$, and average height at hips $-49.5 \mathrm{~cm}$ for all animals. The bulls had a thicker subcutaneous fat layer over the rump than at the 12th-13th rib site. Carcass conformation scores ranged from 4.0 to 9.0 points, which corresponded to conformation class from $\mathrm{O}^{-}$to $\mathrm{R}^{+}$. The carcasses had a low fat content (average fat class $2^{-}$), and muscles were visible along their entire length.

In the next stage, relationships between the analysed traits were determined based on the full dataset (Table 2 ). Highly significant $(\mathrm{P} \leq 0.01)$ positive correlations were noted between independent and dependents variables, in particular between HCW and the majority of traits. The highest value of the correlation coefficient $(\mathrm{R}=0.96)$ was observed between HCW and live body weight. In the group of independent variables, high correlations were found between height at withers and height at sacrum 
$(\mathrm{R}=0.90)$. To prevent collinearity in regression equations, height at withers was excluded from further analyses.

Based on statistical analyses, 11 independent variables were tested in four multiple regression equations for predicting the carcass value of HF bulls (Table 3). Variables that made a statistically significant contribution to the predicted value were retained in the models. Two equations (one and two) were used to estimate HCW. In one of them, the set of independent variables does not include live weight, because estimation of HCW on the farm, before the animals are transported to the abattoir, helps to ensure that the producer receives a fair return. This equation is based on the results of the following zoometric measurements: height at sacrum, chest girth, pelvic width and pelvic length, as well as ultrasound measurement of the thickness of $M$. gluteo-biceps and a visual assessment of muscling in the live animal. The coefficient of determination and standard error of the estimate for the $\mathrm{HCW}$ without live weight (equation one) are $\mathrm{R}^{2}=0.892$ and $\mathrm{S}_{\mathrm{y}}=16.28 \mathrm{~kg}$, respectively.

Table 1. Descriptive statistics of evaluated traits

\begin{tabular}{|c|c|c|c|c|c|c|}
\hline \multirow{2}{*}{ Traits } & \multicolumn{3}{|c|}{ Training set } & \multicolumn{3}{|c|}{ Validation set } \\
\hline & $\mathrm{N}$ & $\overline{\mathrm{x}}$ & $\mathrm{SD}$ & $\mathrm{N}$ & $\overline{\mathrm{x}}$ & SD \\
\hline Age at slaughter (months) & 130 & 22.9 & 1.90 & 37 & 18.5 & 1.86 \\
\hline \multicolumn{7}{|l|}{ Zoometric measurements: } \\
\hline height at withers (cm) & 130 & 135.2 & 5.84 & 37 & 134.1 & 6.41 \\
\hline height at sacrum $(\mathrm{cm})$ & 130 & 138.2 & 5.87 & 37 & 138.1 & 5.76 \\
\hline forechest width $(\mathrm{cm})$ & 130 & 52.3 & 8.61 & 37 & 50.4 & 3.87 \\
\hline chest depth $(\mathrm{cm})$ & 130 & 73.5 & 5.32 & 37 & 72.5 & 3.27 \\
\hline chest girth $(\mathrm{cm})$ & 130 & 200.9 & 11.26 & 37 & 196.4 & 9.11 \\
\hline pelvic width (cm) & 130 & 49.7 & 2.52 & 37 & 48.7 & 2.41 \\
\hline pelvic length $(\mathrm{cm})$ & 130 & 54.8 & 2.85 & 37 & 54.6 & 2.43 \\
\hline trunk length $(\mathrm{cm})$ & 130 & 99.3 & 5.82 & 37 & 96.4 & 4.39 \\
\hline \multicolumn{7}{|l|}{ Ultrasound measurements: } \\
\hline thickness of subcutaneous rump fat (mm) & 130 & 7.7 & 2.64 & 37 & 7.8 & 2.37 \\
\hline thickness of $M$. gluteo-biceps (mm) & 130 & 69.0 & 14.77 & 37 & 64.5 & 14.44 \\
\hline cross-sectional area of $M$. longissimus dorsi $\left(\mathrm{cm}^{2}\right)$ & 130 & 78.6 & 14.34 & 37 & 76.8 & 15.08 \\
\hline thickness of subcutaneous back fat (mm) & 130 & 5.8 & 2.03 & 37 & 5.5 & 1.52 \\
\hline thickness of $M$. longissimus dorsi (mm) & 130 & 69.4 & 11.15 & 37 & 65.7 & 10.31 \\
\hline Intravital muscle scoring (points) & 130 & 5.9 & 1.68 & 37 & 5.9 & 1.07 \\
\hline Live weight $(\mathrm{kg})$ & 130 & 630.7 & 72.32 & 37 & 604.7 & 67.78 \\
\hline Hot carcass weight $(\mathrm{kg})$ & 130 & 329.0 & 39.24 & 37 & 313.6 & 37.33 \\
\hline $\begin{array}{l}\text { Conformation class according to the EUROP system } \\
\text { (points) }\end{array}$ & 130 & 6.4 & 1.30 & 37 & 6.1 & 1.06 \\
\hline Fat class according to the EUROP system (points) & 130 & 4.6 & 1.27 & 37 & 4.6 & 0.92 \\
\hline
\end{tabular}

EUROP conformation: 1 - $\mathrm{P}^{-}, 15-\mathrm{E}^{+-}$; EUROP degree of fat cover: 1 - $1^{-}$(no up to low fat cover), $15-5^{+}$ (very high). 


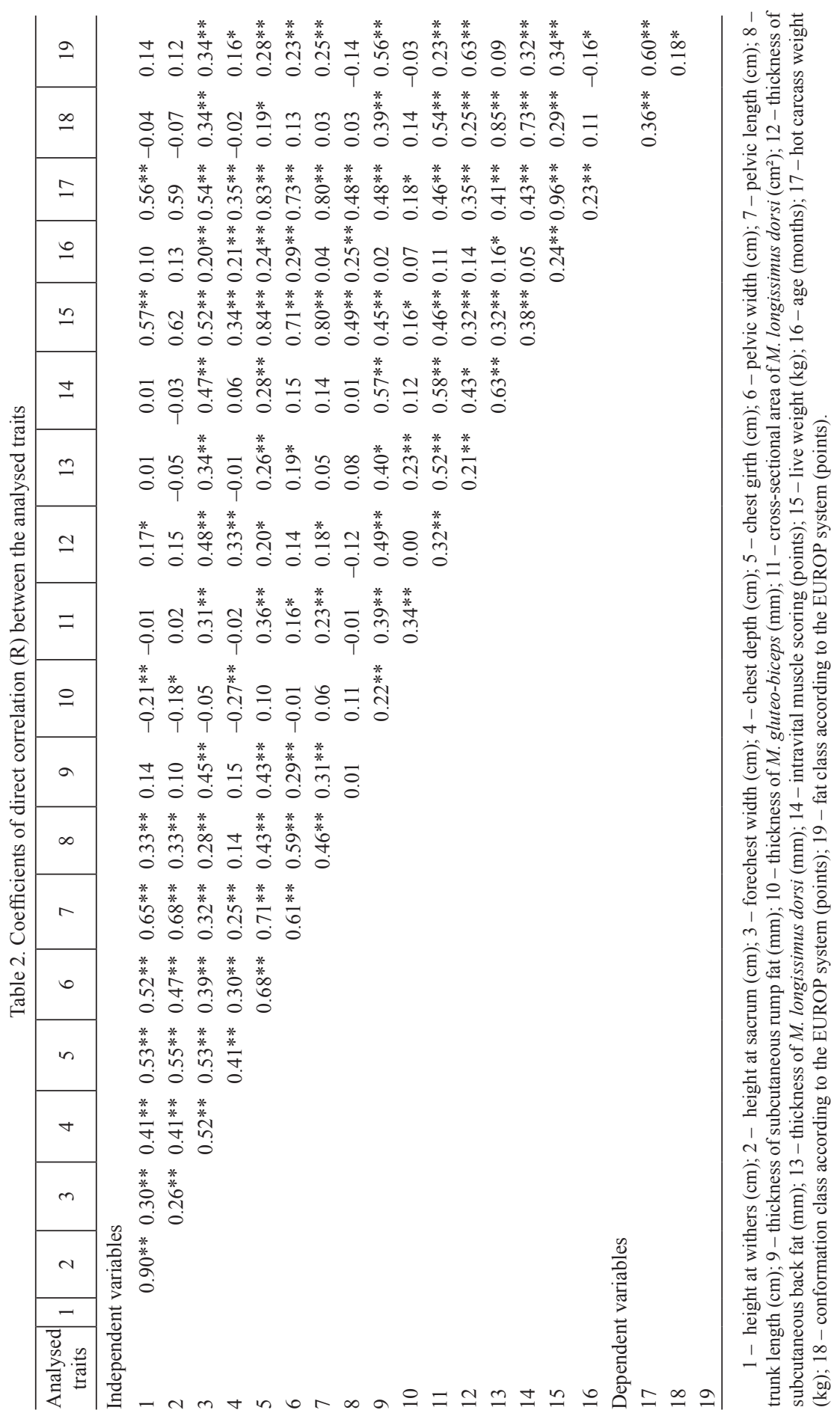




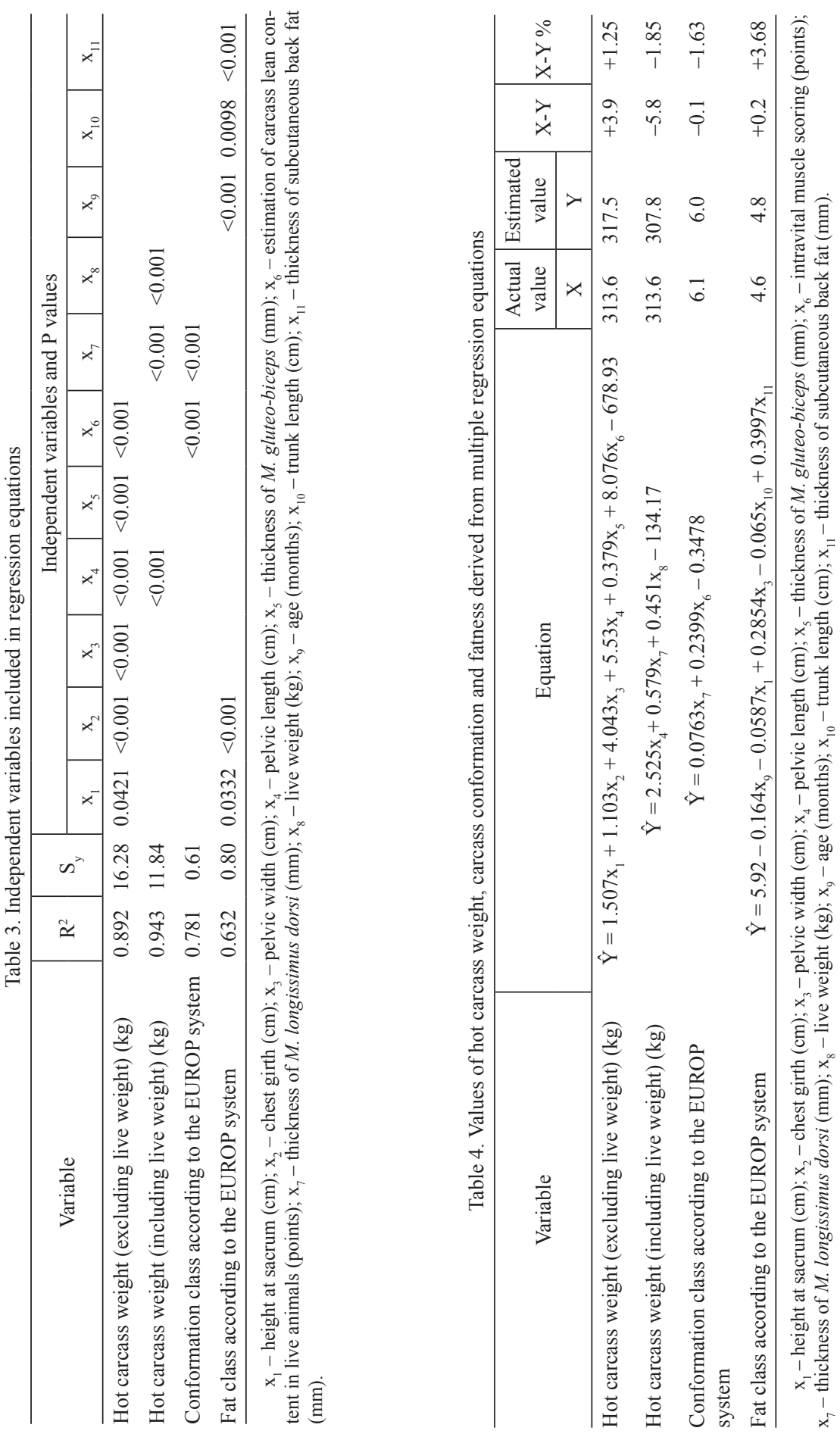


The equation with bull's live weight as an independent variable had a higher coefficient of determination $\left(\mathrm{R}^{2}=0.943\right)$ and a lower standard error of the estimate $\left(\mathrm{S}_{\mathrm{y}}=11.84 \mathrm{~kg}\right)$. The shortest equation, formulated to predict carcass conformation according to the EUROP system, included the results of ultrasound measurement of the thickness of $M$. lon-gissimus dorsi and a visual assessment of muscling in the live animal. Carcass fatness was estimated using the equation with the lowest coefficient of determination $\left(\mathrm{R}^{2}=0.632\right)$ and standard error of the estimate $\left(\mathrm{S}_{\mathrm{y}}=0.80\right)$. The accuracy of equations was verified on 37 bulls from the validation set. The equation for estimating $\mathrm{HCW}$, with the use of bull's live weight, underestimated the final value by $1.85 \%$ $(-5.8 \mathrm{~kg})$ on average. The reverse trend was observed in the equation which did not include bull's live weight - the predicted value was overestimated by $1.25 \%$ on average. The equation designed for estimating EUROP carcass conformation, based on a visual assessment of muscling in the live animal and ultrasound measurement of the thickness of M. longissimus dorsi, provided the most accurate results. The difference between the actual and predicted carcass conformation was only 0.1 point on a 15 -point scale.

\section{Discussion}

The variables used in the proposed equations represent slaughter and live animal traits. In a study by Conroy et al. (2009), trunk length and pelvic length were highly significantly correlated with carcass weight and fat class, and negatively with the proportion of valuable cuts in the carcass and conformation class (only pelvic length). Similarly in the current experiment highly significant correlations were found between HCW and trunk and pelvic length and also between fat class and pelvic length. A negative correlation was observed between carcass fat class and trunk length. The strongest correlations were observed between live weight and $\mathrm{HCW}(\mathrm{R}=0.96)$. Slightly lower values of correlation between slaughter weight and carcass weight $(\mathrm{R}=0.94)$ were reported by Młynek and Litwińczuk (1999). Bergen et al. (2005) demonstrated that the inclusion of height at sacrum in the prediction model increased the estimation accuracy of lean meat yield in the carcass, which was not observed in our study. Most coefficients of correlation between exterior traits and carcass traits were significant (average level of correlation).

Ultrasound measurement of the cross-sectional area of M. longissimus dorsi is strongly correlated with its actual value measured post mortem, $\mathrm{R}=0.86$ (Greiner et al., 2003a), $\mathrm{R}=0.66-0.75$ (Baker et al., 2006), $\mathrm{R}=0.83$ (Török et al., 2009), and with lean meat yield (Bergen et al., 2003; Tait et al., 2005). In the present study, a highly significant correlation was noted between the above measurement and live muscle scoring, and conformation class. Live muscle scoring was highly significantly $(\mathrm{R}=0.63)$ correlated with the thickness of $M$. longissimus dorsi. This trait is also significantly correlated with carcass weight (Blanco Roa et al., 2003), conformation class and the percentage content of valuable cuts in the carcass (Conroy et al., 2009). 
Cochran and Cox (1957) defined the accuracy of ultrasound measurement as the closeness with which it approaches the true value. They also found that a high estimation error does not affect the precision of measurement, but it reduces its accuracy. In the present study, equation 2 for estimating HCW with bull's live weight as a variable was characterized by a higher determination coefficient $\left(\mathrm{R}^{2}\right)$ and a lower standard error, in comparison with equation 1 where bull's live weight was not used ( 0.943 and 0.892 , respectively). However, validation did not confirm the advantage of equation 2 over equation 1. Ultrasound measurements tend to overestimate carcass fatness and underestimate the area of $M$. longissimus dorsi (Charagau et al., 2000).

Baker et al. (2006) proposed a series of equations to estimate the total fat content of carcasses in young bulls. The unavailability of post-slaughter measurements limited the practical application of the derived equations. Therefore, a new variable was proposed - predicted hot carcass weight $(\mathrm{pHCW})$. Although in the final equation the results of ultrasound measurements were used together with $\mathrm{pHCW}$, the coefficient of determination was $\mathrm{R}^{2}=0.62$; the performed experiment confirmed that ultrasound examinations can be used for predicting the body composition of bulls. Thus, in our study ultrasound measurements were included in the equations used for estimating $\mathrm{HCW}$. Those equations and the equations for predicting conformation class did not include data on subcutaneous fat thickness over the rump, which were considered statistically non-significant. Bergen et al. (2005) reported that the use of thickness of subcutaneous rump fat as a variable decreases the standard error of estimation.

In the present study, the equation predicting carcass conformation under the EUROP scheme was characterized by the lowest error of estimation although it used the results of a visual assessment of muscling which is a subjective method. The suitability of this trait was confirmed by Drennan et al. (2008) who noted a highly significant correlation between a visual assessment of muscling in the live animal and carcass conformation and fat classes $(\mathrm{R}=0.66-0.74$, depending on the grader and the number of evaluated sites). Previous experiments conducted by Drennan et al. (2007) revealed a correlation of $\sim 0.70$ between a visual assessment of muscling in the live animal and carcass dressing percentage. The low standard error of estimation in equation 3 (Table 3 ) resulted also from the fact that the thickness of M. longissimus dorsi determined ultrasonographically is strongly correlated with carcass conformation (Conroy et al., 2009).

In conclusion, selected ultrasound measurements (thickness of M. gluteo-biceps, thickness of $M$. longissimus dorsi, thickness of subcutaneous back fat), zoometric measurements (height at sacrum, chest girth, pelvic width, pelvic length, trunk length) and intravital muscle scoring of HF bulls from a semi-intensive production system, slaughtered at the age of 15-27 months, can be used in formulating multiple regression equations for predicting the carcass value of live animals. The proposed equations enable predicting the carcass value of young HF bulls with satisfactory accuracy, thus contributing to an objective live beef cattle assessment. 


\section{References}

B a ke r M.J., Ted e s chi L.O., F ox D.G., Henning W.R., K e t c he n D.J. (2006). Using ultrasound measurements to predict body composition of yearling bulls. J. Anim. Sci., 84: 2666-2672.

B ergen R., Crew s Jr. D.H., Miller S.P., M c K in no n J.J. (2003). Predicting lean meat yield in beef cattle using ultrasonic muscle depth and width measurements. Can. J. Anim. Sci., 83: 429-434.

B ergen R., Miller S.P., Mandell I.B., R oberts on W.M. (2005). Use of live ultrasound, weight and linear measurements to predict carcass composition of young beef bulls. Can. J. Anim. Sci., 85: 23-35.

Blanco Roa N.E., Huba J., Polák P., Hetényi L., Peškovičová D., B ahelka I. (2003). Comparison of differences in muscle depth and possibilities to predict some parameters of carcass value in bulls by an ultrasonographic method. Czech J. Anim. Sci., 48: 338-343.

B re th o u r J.R. (2000). Using serial ultrasound measures to general model of marbling and backfat thickness changes in feedlot cattle. J. Anim. Sci., 78: 2055-2061.

Ch a ra ga u P.K., C rew s Jr. D.H., K e m p R.A., M w a n s a P.B. (2000). Machine effect on accuracy of ultrasonic prediction of backfat and ribeye area in beef bulls, steers and heifers. Can. J. Anim. Sci., 80: 19-24.

Choroszy Z., Grodzki G., Choroszy B., Szewczyk A., Stachyra M. (2010). Evaluation of beef cattle conformation in Poland - method description (in Polish). Prz. Hod., 8: 1-4.

C o c hr a n W.G., C o x G.M. (1957). Experimental Design (2nd Ed.). John Wiley \& Sons, New York.

Conroy S.B., Drennan M.J., Kenny D.A., M c G e e M. (2009). The relationship of live animal muscular and skeletal scores, ultrasound measurements and carcass classification scores with carcass composition and value in steers. Animal, 3: 1613-1624.

Conroy S.B., Drennan M.J., Kenny D.A., McGee M. (2010). The relationship of various muscular and skeletal scores and ultrasound measurements in the live animal, carcass classification scores with carcass composition and value of bulls. Livest. Sci., 127: 11-21.

Drennan M.J., Ke ane M.G., McGee M. (2007). Relationship of live animal scores/measurements and carcass grades with carcass composition and carcass value of steers. In: Evaluation of carcass and meat quality in cattle and sheep, Lazzaroni C., Gigli S., Gabina D. (eds). Wageningen Academic Publishers, EAAP publication, 123, pp. 159-169.

Drennan M.J., M c G e e M., K e a n e M.G. (2008). The value of muscular and skeletal scores in the live animal and carcass classification scores as indicators of carcass composition in cattle. Animal, 2: 752-760.

Gi 1 Z., A d a m c z y k K., G o lon ka M., Z a p l e t a 1 P., Ch or o s z y Z. (2007). Prediction of dressing percentage in young cattle based on pre-slaughter evaluation of selected traits (in Polish). Rocz. Nauk. Zoot., 34: 13-19.

Gre in er S.P., Rous e G.H., Wils on D.E., Cund iff L.V., Wh e ele r T.L. (2003 a). The relationship between ultrasound measurements and carcass fat thickness and longissimus muscle area in beef cattle. J. Anim. Sci., 81: 676-682.

Gre in e r S.P., R o u s e G.H., Wil s on D.E., C un d iff L.V., Wh e e le r T.L. (2003 b). Prediction of retail product weight and percentage using ultrasound and carcass measurements in beef cattle. J. Anim. Sci., 81: 1736-1742.

Guidelines for Uniform Beef Improvement Programs. Ninth Edition. 2010. Beef Improvement Federation. http:/www.beefimprovement.org/content/uploads/2013/07/Master-Edition-of-BIF-Guidelines-Updated-12-17-2010.pdf

Ind u r a in G., C arr T.R., G on i M.V., In s a u s t i K., B eri a in M.J. (2009). The relationship of carcass measurements to carcass composition and intramuscular fat in Spanish beef. Meat Sci., 82: $155-161$.

M c K i e rn a n B. (2007). Muscle scoring beef cattle. NSW Department of Primary Industries, New South Wales, Australia, http:www.dpi.nsw.gov.au/_data/ assets/pdf_file/0006/103938/musclescoring-beef-cattle.pdf

Mły n e k K., L i tw i ń c zu k Z. (1999). Suitability of zoometric measurements and conformation indices for evaluating slaughter value of cattle slaughtered at around $5000 \mathrm{~kg}$ body weight (in Polish). Zesz. Nauk. Prz. Hod., 44: 343-351. 
Realini C.E., Williams R.E., Prongle T.D., Bertrand J.K. (2001). Gluteus medius and rump fat depths as additional live animal ultrasound measurements for predicting retail product and trimmable fat in beef carcasses. J. Anim. Sci., 79: 1378-1385.

Słoniewski K., Dymnicki E., Sakowski T., Oprządek J., Oprządek A. (2001). Use of in vivo ultrasound measurements for predicting the slaughter value of beef bulls. Anim. Sci. Pap. Rep., 19: 57-64.

Ta it R.G. Jr., Wils on D.E., R ou s e G.H. (2005). Prediction of retail product and trimmable fat yields from the four primal cuts in beef cattle using ultrasound or carcass data. J. Anim. Sci., 83: $1353-1360$.

Tör ö k M., P o 1 g á r J.P., K o s c i G., F a r k a s V., S z a bó F. (2009). Correlation of ultrasonic measured ribeye area and fat thickness to the certain traits measured on slaughter bulls (Short Communication). Arch. Tierz., 52: 23-27.

Tre l a J., C h or os zy B. (2011). The work of the National Research Institute of Animal Production in beef livestock production (in Polish). Wiad. Zoot., XLIX, 4: 11-56.

Received: 11 V 2013

Accepted: 27 VIII 2013 